University of Windsor

Scholarship at UWindsor

$9-1-2017$

\title{
Differential invasion success in aquatic invasive species: the role of within- and among-population genetic diversity
}

\author{
Kyle W. Wellband \\ Great Lakes Institute for Environmental Research \\ Harri Pettitt-Wade \\ Great Lakes Institute for Environmental Research \\ Aaron T. Fisk \\ Great Lakes Institute for Environmental Research \\ Daniel D. Heath \\ Great Lakes Institute for Environmental Research
}

Follow this and additional works at: https://scholar.uwindsor.ca/glierpub

Part of the Biochemistry, Biophysics, and Structural Biology Commons, Biodiversity Commons, Biology Commons, and the Marine Biology Commons

\section{Recommended Citation}

Wellband, Kyle W.; Pettitt-Wade, Harri; Fisk, Aaron T.; and Heath, Daniel D.. (2017). Differential invasion success in aquatic invasive species: the role of within- and among-population genetic diversity. Biological Invasions, 19 (9), 2609-2621.

https://scholar.uwindsor.ca/glierpub/215

This Article is brought to you for free and open access by the Great Lakes Institute for Environmental Research at Scholarship at UWindsor. It has been accepted for inclusion in Great Lakes Institute for Environmental Research Publications by an authorized administrator of Scholarship at UWindsor. For more information, please contact scholarship@uwindsor.ca. 


\title{
Differential invasion success in aquatic invasive species: the role of within- and among-population genetic diversity
}

\author{
Kyle W. Wellband (D) Harri Pettitt-Wade $\cdot$ Aaron T. Fisk $\cdot$ Daniel D. Heath
}

Received: 14 December 2016/Accepted: 30 May 2017/Published online: 8 June 2017

(C) Springer International Publishing AG Switzerland 2017

\begin{abstract}
Despite a well-developed theoretical basis for the role of genetic diversity in the colonization process, contemporary investigations of genetic diversity in biological invasions have downplayed its importance. Observed reductions in genetic diversity have been argued to have a limited effect on the success of establishment and impact based on empirical studies; however, those studies rarely include assessment of failed or comparatively less-successful biological invasions. We address this gap by comparing genetic diversity at microsatellite loci for taxonomically and geographically paired aquatic invasive species. Our four species pairs contain one highly successful and one less-successful invasive species (Gobies: Neogobius melanostomus, Proterorhinus semilunaris; waterfleas: Bythotrephes longimanus, Cercopagis pengoi; oysters: Crassostrea gigas, Crassostrea virginica; tunicates: Bortylloides violaceous,
\end{abstract}

Electronic supplementary material The online version of this article (doi:10.1007/s10530-017-1471-8) contains supplementary material, which is available to authorized users.

K. W. Wellband · H. Pettitt-Wade · A. T. Fisk ·

D. D. Heath $(\square)$

Great Lakes Institute for Environmental Research, University of Windsor, 401 Sunset Ave., Windsor, ON N9B 3P4, Canada

e-mail:dheath@uwindsor.ca

D. D. Heath

Department of Biological Sciences, University of Windsor, Windsor, Canada
Botryllus schlosseri). We genotyped 2717 individuals across all species from multiple locations in multiple years and explicitly test whether genetic diversity is lower for less-successful biological invaders within each species pair. We demonstrate that, for gobies and tunicates, reduced allelic diversity is associated with lower success of invasion. We also found that lesssuccessful invasive species tend to have greater divergence among populations. This suggests that intraspecific hybridization may be acting to convert among-population variation to within-population variation for highly successful invasive species and buffering any loss of diversity. While our findings highlight the species-specific nature of the effects of genetic diversity on invasion success, they do support the use of genetic diversity information in the management of current species invasions and in the risk assessment of potential future invaders.

Keywords Alpha diversity - Beta diversity - Nonindigenous $\cdot$ Neutral genetic variation

\section{Introduction}

There has long been an interest in the impact of colonization processes on genetic diversity of species and in turn how levels and patterns of genetic diversity influence species' colonization potential (Baker and Stebbins 1965; Barrett 2015). There is a well-established theoretical basis for the role of genetic diversity 
in promoting both the adaptive potential of populations (Fisher 1930) and the viability of populations through the maintenance of heterozygosity (Charlesworth and Charlesworth 1987), both of which may be critical components of the successful colonization of novel environments. Propagule pressure (the number of organisms transported) is widely believed to have an important influence on colonization success (Lockwood et al. 2005) with consequences for the genetic diversity of colonizers. Theory predicts that founder effects and bottlenecks associated with colonization events should lead to stochastic reductions in diversity as a result of genetic drift (Nei et al. 1975). The predicted loss of diversity is expected to have the potential to compromise the ability of species to establish, either by reducing standing genetic variation that inhibits adaptive potential, or by exposing populations to the negative effects of inbreeding (Sakai et al. 2001). Biological invasions are human mediated examples of colonization that often result in ecological or economic harm in introduced ranges. In an effort to predict and minimize the risk of future invasions and mitigate the impacts of currently established invaders, there has been considerable interest in quantifying the role genetic diversity plays in determining invasion success or impact.

The advent of molecular genetic tools has facilitated the characterization of genetic diversity of biological invaders. Quantitative meta-analyses of over 80 studies across a diverse range of taxa have determined that modest genetic bottlenecks are indeed a common feature of invasions (Dlugosch and Parker 2008; Uller and Leimu 2011). In contrast, biological invasions do not appear to cause reductions in phenotypic variation (Dlugosch and Parker 2008). Reductions of genetic diversity do not appear to broadly limit adaptive potential as adaptation during invasions also appears to be common (Bock et al. 2015; Colautti and Lau 2015) and has been demonstrated even in the face of severe founder effects (Kolbe et al. 2012). It appears the relationship between genetic diversity and invasion success is more complex than previously thought. The importance of genetic diversity for the viability of invasive populations will depend on the number of genes that underlie ecologically relevant traits, the fitness contributions of alleles for these genes in different environments, and the interaction of alleles among these loci (Dlugosch et al. 2015). These factors will determine whether the effects of genetic drift (e.g. loss of genetic diversity) during the invasion process or issues of evolutionary history (e.g. low genetic diversity in the native range) are important for the variability of traits in introduced regions, and in turn, viability of invasive populations (Dlugosch et al. 2015). Thus, while neutral genetic diversity is not an ideal proxy for genome-wide genetic diversity (He et al. 2016) and does not universally correlate with invasion success, there is certainly evidence that reduced genetic diversity can be a limiting factor in the success of biological invasions (Kinziger et al. 2011; Signorile et al. 2014).

While reduced genetic diversity does not appear to universally prevent invasion success, low genetic diversity may increase the probability of invasion failure. Despite a number of studies quantifying genetic diversity in invasive species, research on failed invasions is generally lacking (Zenni and Nuñez 2013). Furthermore, there is little data regarding the role of genetic diversity in failed invasions (Dlugosch and Parker 2008). There is only one quantitative review of genetic diversity in invasive species that incorporates metrics of invasion success (Uller and Leimu 2011); however, that meta-analysis was skewed toward examples of highly successful invasions. This bias almost certainly reflects the greater interest in the most ecologically and economically damaging species, not to mention the difficulties associated with collecting data on species that do not exist (failed to establish), or those with low population density and restricted distributions. As a result, there is a general deficit of studies on the factors associated with failed invasions. Studies of that sort would provide crucial data on the process of successful colonization and the establishment of invasive populations.

To address this knowledge gap, we investigate the relationship between neutral genetic diversity and invasion success for four pairs of invasive species. We chose pairs of species to represent the broad taxonomic (mollusc, crustacean, tunicate, fish) and geographic (Atlantic and Pacific Oceans and Laurentian Great Lakes) ranges of aquatic invasive species (AIS) in North America. Species pairs were selected to compare a highly successful invader (stage 5: widespread and dominant; Colautti and MacIsaac 2004) to a less-successful invader (stage 3: established or stage 4a: widespread but not dominant; Colautti and 
MacIsaac 2004), while controlling for differences in morphology, ecology, taxonomy, and geography of the invasions. Species pairs (successful/less-successful) include: from the Laurentian Great Lakes, round goby Neogobius melanostomus/tubenose goby Proterorhinus semilunaris and spiny waterflea Bythotrephes longimanus/fishhook waterflea Cercopagis pengoi; from the Northeast Pacific Ocean, Pacific oyster Crassostrea gigas/Eastern oyster Crassostrea virginica and from the Northwest Atlantic Ocean, violet tunicate Bortylloides violaceous/golden star tunicate Botryllus schlosseri.

Both species of gobies were introduced in the early 1990s to the St. Clair River (Jude et al. 1992). Since then, $N$. melanostomus has rapidly spread throughout all the Laurentian Great Lakes and many of their tributaries and become a dominant member of the ecosystem. In contrast $P$. semilunaris has subsequently been transported to other sites but only occurs at low density in isolated sites (Kocovsky et al. 2011; Grant et al. 2012). Both species are ecologically similar, occupying the same habitats in the Great Lakes with similar but non-overlapping dietary niches (Pettitt-Wade et al. 2015). B. longimanus was introduced in the late 1980s (Johannsson et al. 1991) and has spread throughout the Laurentian Great Lakes and into over 150 smaller inland lakes (Yan et al. 2011). C. pengoi were introduced in 1998 (MacIsaac et al. 1999) and are present primarily in nearshore areas of the Great Lakes and in the Finger Lakes of New York State (Therriault et al. 2002). These species are ecologically and morphologically similar zooplanktivores that differ primarily in size (Ptáčniková et al. 2015). On the east coast of North America, B. schlosseri have been present since at least the early 1900s and is considered generally rare in Canadian waters (Carver et al. 2006). In contrast, B. violaceous was first detected in Canada in 2001 and has rapidly spread throughout the Atlantic Provinces (Carver et al. 2006). Both species are similar-sized sessile filter-feeding colonial organisms that co-occur at many sites and have similar sized and partially overlapping dietary niches (Pettitt-Wade 2016). Little additional information is available to suggest that these species are dramatically ecologically different (Carver et al. 2006). On the west coast of Canada, both $C$. gigas and $C$. virginica were introduced in the late 1800s; however, C. gigas has established self-sustaining populations throughout the Strait of Georgia whereas $C$. virginica has remained isolated to one site at the mouth of the Serpentine River in Boundary Bay (Ruesink et al. 2005; Gillespie 2007). Both species are sessile filterfeeders and ecosystem engineers that develop reefs (Ruesink et al. 2005).

With the exception of $C$. virginica, whose invasive distribution is restricted to one site, we sampled multiple locations throughout the invasive range of all species over multiple years. If genetic diversity is indeed a factor limiting successful range expansion we predict that reduced genetic diversity within populations ( $\alpha$ diversity) will be associated with the lesssuccessful invader in each pair. In contrast, we expect that diversity among populations ( $\beta$ diversity) will be higher for less-successful species reflecting lower connectivity among populations. The results of this study will help clarify the role of genetic diversity in contributing to colonization or invasion failure of species. In addition, they will inform the use of genetic diversity in the management of current invasive species and its utility in the risk assessment of potential future species invasions. This research also provides insights on the broader conservation of organisms and understanding the contribution of molecular genetic diversity to marginal population viability.

\section{Methods}

Samples for each AIS were collected throughout their introduced ranges in Canada from a variety of sites and across 3 years (Table 1). Collection methods were species-pair specific. Briefly, oysters were collected from the intertidal zone at low tide and a small piece of gill tissue was dissected and preserved in a homemade high salt solution (5.3 M Ammonium Sulfate, $25 \mathrm{mM}$ Sodium Citrate, $20 \mathrm{mM}$ Ethylenediaminetetraacetic acid, $\mathrm{pH}$ 5.2). Individual isolated tunicate colonies were collected by divers and preserved in high salt solution. Waterfleas were collected using vertical hauls with a $50 \mathrm{~cm}$ diameter plankton net with $80 \mu \mathrm{m}$ mesh. Plankton samples were concentrated and preserved at a ratio of $1: 10$ in high salt solution. Individuals were later isolated and identified to species under a dissection microscope. Gobies were collected using a combination of angling, seine netting and baited minnow traps. Fish were euthanized in an 
Table 1 Sampling location and number of individuals collected for eight invasive species from 2011 to 2013

\begin{tabular}{|c|c|c|c|c|c|c|c|}
\hline Taxa & N. Loci & Site & Lat. & Long. & 2011 & 2012 & 2013 \\
\hline \multicolumn{8}{|c|}{ Gobies-Great Lakes } \\
\hline \multirow[t]{8}{*}{ N. melanostomus } & \multirow[t]{8}{*}{9} & Collingwood, ON & 44.515 & -80.228 & 49 & & 49 \\
\hline & & Windsor, ON & 42.307 & -83.075 & & 50 & 49 \\
\hline & & Hamilton, ON & 43.301 & -79.795 & 48 & 49 & \\
\hline & & Thunder Bay, ON & 46.772 & -92.087 & 44 & 49 & \\
\hline & & Nanticoke, ON & 42.797 & -80.066 & 49 & & 50 \\
\hline & & Port Elgin, ON & 44.446 & -81.405 & 48 & & 50 \\
\hline & & Tobermory, ON & 45.257 & -81.662 & & 43 & 46 \\
\hline & & Seymour Lake, ON & 44.387 & -77.804 & 48 & & 44 \\
\hline \multirow[t]{2}{*}{ P. semilunaris } & \multirow[t]{2}{*}{9} & Lake St. Clair, ON & 42.474 & -82.413 & 23 & 28 & \\
\hline & & Thunder Bay, ON & 48.375 & -89.212 & & 47 & \\
\hline \multicolumn{8}{|c|}{ Tunicates-Atlantic Coast } \\
\hline \multirow[t]{7}{*}{ B. violaceous } & \multirow[t]{7}{*}{10} & Chester Harbour, NS & 44.536 & -64.242 & 39 & 39 & \\
\hline & & Dingwall, NS & 46.903 & -60.460 & 43 & 43 & \\
\hline & & Lockeport, NS & 43.701 & -65.111 & 43 & 47 & \\
\hline & & Lunenburg, NS & 44.375 & -64.310 & 40 & 44 & \\
\hline & & North Sydney, NS & 46.191 & -60.268 & 38 & 34 & \\
\hline & & Petit de Grat, NS & 45.506 & -60.961 & 34 & 39 & \\
\hline & & Yarmouth Bar, NS & 43.816 & -66.149 & 44 & 20 & \\
\hline \multirow[t]{5}{*}{ B. schlosseri } & \multirow[t]{5}{*}{7} & Halifax Yacht Club, NS & 44.622 & -63.581 & 30 & 22 & \\
\hline & & Little Harbour, NS & 44.709 & -62.842 & 39 & 25 & \\
\hline & & Lockeport, NS & 43.701 & -65.111 & 33 & 17 & \\
\hline & & Little River, NS & 44.444 & -66.129 & 32 & 25 & \\
\hline & & Petit de Grat, NS & 45.506 & -60.961 & 19 & 22 & \\
\hline \multicolumn{8}{|c|}{ Oysters-Pacific Coast } \\
\hline \multirow[t]{4}{*}{ C. gigas } & \multirow[t]{4}{*}{8} & Buckley Bay, BC & 49.526 & -124.848 & 42 & 41 & \\
\hline & & Quadra Island, BC & 50.103 & -125.211 & 33 & 46 & \\
\hline & & Vancouver, BC & 49.298 & -123.121 & 15 & 17 & \\
\hline & & Thetis Island, BC & 48.983 & -123.670 & 56 & 73 & \\
\hline C. virginica & 9 & Serpentine River, BC & 49.087 & -122.819 & 34 & 30 & \\
\hline \multicolumn{8}{|c|}{ Waterfleas-Great Lakes } \\
\hline \multirow[t]{6}{*}{ B. longimanus } & \multirow[t]{6}{*}{9} & Collingwood, ON & 44.523 & -80.230 & 45 & & 47 \\
\hline & & Erieau, ON & 42.166 & -81.806 & 25 & & 16 \\
\hline & & Kashawakamak Lake, ON & 44.865 & -77.046 & 47 & & 46 \\
\hline & & Lake Simcoe, ON & 44.463 & -79.461 & 50 & & 28 \\
\hline & & Port Elgin, ON & 44.444 & -81.422 & 48 & & 48 \\
\hline & & Upper Stoney Lake, ON & 44.574 & -78.061 & 43 & & 44 \\
\hline \multirow[t]{2}{*}{ C. pengoi } & \multirow[t]{2}{*}{8} & Bay of Quinte, ON & 44.235 & -76.906 & 44 & & 44 \\
\hline & & Nanticoke, ON & 42.796 & -80.059 & 34 & & 47 \\
\hline
\end{tabular}

Geographic location (site) is the nearest community and specific coordinates for each site are given: Lat. latitude, Long. longitude. N. Loci number of microsatellite loci genotyped for each species

overdose solution of MS-222 (Finquel, Argent Laboratories, Redmond, WA) and a fin clip was preserved in high salt solution.
DNA was extracted from collected tissue using a modified binding column protocol (Elphinstone et al. 2003). We genotyped organisms at 7-10 species- 
specific microsatellite loci (Supplemental Table 1) using the following PCR conditions: $20 \mathrm{mM}$ Tris- $\mathrm{HCl}$ $\mathrm{pH} 8.75,10 \mathrm{mM} \mathrm{KCl}, 10 \mathrm{mM}\left(\mathrm{NH}_{4}\right)_{2} \mathrm{SO}_{4}, 0.1 \%$ Triton X-100, $0.1 \mathrm{mg} / \mathrm{mL}$ BSA, $200 \mu \mathrm{M}$ each dNTP, $200 \mathrm{nM}$ forward and reverse primers, locus specific $\mathrm{MgSO}_{4}$ concentrations (see Supplemental Table 1), $0.5 \mathrm{U}$ of Taq polymerase (Bio Basic Canada Inc., Markham, ON) and 10-20 ng of gDNA. Themocycling conditions were $95{ }^{\circ} \mathrm{C}$ for $2 \mathrm{~min}, 35$ cycles of $95{ }^{\circ} \mathrm{C}$ for $15 \mathrm{~s}$, locus specific annealing temperature (see Supplemental Table 1) for $15 \mathrm{~s}$ and $72{ }^{\circ} \mathrm{C}$ for $30 \mathrm{~s}$, followed by $72{ }^{\circ} \mathrm{C}$ for $5 \mathrm{~min}$. PCR products were electrophoresed using a Licor 4300 DNA Analyzer (Licor Biosciences Inc.) and fragment sizes determined using Gene ImagR software (Scanalytics Inc.). For genetic diversity analyses we only included individuals with a genotype for at least $75 \%$ of the microsatellite markers for that species. While 7-10 microsatellite markers may be insufficient to precisely estimate genome-wide variability, the markers were chosen randomly thus our results should be unbiased and conservative estimates of differences we detect.

We characterized multiple metrics of genetic diversity. These metrics were broadly grouped as measures of within-population diversity ( $\alpha$ diversity) or measures of among population diversity ( $\beta$ diversity). For $\alpha$ diversity, basic summary statistics of allelic data were generated for each microsatellite locus for each population in each year. We characterized the number of alleles and observed heterozygosity using the 'adegenet' v2.0.1 package (Jombart 2008) and allelic richness (rarefied number of alleles per 15 individuals) using the 'hierfstat' v0.04-22 package (Goudet and Jombart 2015) in R v3.3.1 ( $\mathrm{R}$ Core Team 2016). A fixed number of individuals was used for allelic richness rarefaction to allow for cross species comparisons and was chosen based on the smallest study-wide population sample size (Table 1). We also determined effective population sizes of invasive populations using the linkage-disequilibrium method of Waples and Do (2008) for random mating populations as implemented in NeEstimator v2.01 (Do et al. 2014) with default parameters.

For $\beta$ diversity, we determined the genetic homogeneity of invasive populations using the global $\mathrm{F}_{\mathrm{ST}}$ across all samples per locus using Wier and Cockerham's theta (1984) as implemented in 'pegas' v0.9 (Paradis 2010). We also calculated the average pairwise $F_{S T}$ using the same estimator for each population in each year using 'hierfstat' v0.04-22 (Goudet and Jombart 2015). We characterized first generation migrants based on the $\mathrm{L}_{\text {home }} / \mathrm{L}_{\max }$ ratio (likelihood of the genotype originating from the sampled population divided by the maximum such likelihood for a genotype originating from any sampled population) of Paetkau et al. (2004) and the likelihood criteria of Rannala and Mountain (1997). The probability of an individual's assignment to the population from which it was sampled was determined using a Monte Carlo resampling procedure (10,000 simulated individuals, Paetkau et al. 2004). Individuals that had less than a $5 \%$ probability of originating from the population where they were sampled were identified as first generation migrants. Due to differences in sample size among populations and species, we expressed the number of first generation migrants as a proportion of migrants per individuals sampled for each population.

To quantify the conversion of $\beta$ diversity into $\alpha$ diversity we measured the level of admixture, or more accurately intraspecific hybridization. We used a technique called Discriminant Analysis of Principal Components (DAPC; Jombart et al. 2010) to organize individuals into genetic clusters based on allele frequency variation summarized by principal components. This technique is a naïve approach to characterizing population structure, similar to the popular software STRUCTURE; however, DAPC does not make any assumptions about migration-drift equilibrium (Jombart et al. 2010) thus making it more appropriate for the analysis of invasive species. As with many clustering routines, the choice of the number of meaningful clusters is partially subjective. DAPC uses changes in Bayesian Information Criterion to aid in the choice of the number of cluster (Jombart et al. 2010). We attempted to keep the number of clusters similar within species pairs to avoid confounding the number of clusters with admixture proportions assigned. Most species exhibited an exponential decrease in the BIC as more clusters were added, thus we chose to use a number of clusters (three) that represents a trade-off between explaining maximal variation while still representing a meaningful biological reality (Jombart et al. 2010). We used two clusters to explain population structure for species (C. pengoi and C. virginica) where there was clear evidence three clusters was not supported. We then quantified admixture for an individual as the 
maximum proportion of ancestry (from the posterior distribution) that assigned to any cluster. Thus our measure of admixture represents the average proportion of individuals' genetic backgrounds that can be attributed to one genetic grouping.

\section{Statistical analyses}

To assess the relationship between genetic diversity and invasion success we analyzed each species-pair separately for each measure of genetic diversity. For measures of $\alpha$ diversity that are available at the level of individual loci within populations (number of alleles, observed heterozygosity and allelic richness) we used general linear mixed models as implemented in the 'Ime4' v1.1-12 package (Bates et al. 2015) in R. Models were fit with a random-factor for locus and fixed effects for year and relative invasion success (highly successful species versus less-successful species in each of the paired species comparisons) with population as replicates. For the paired oysters, the less-successful species only occurs at one geographic location in Canada (Gillespie 2007) and thus we used the temporal samples as replicates for this species. While this represents a form of pseudoreplication and may result in a non-conservative comparison, we report the means and variances for all parameters to allow readers to draw their own qualitative conclusions. We tested for the significance of effects in the model using likelihood ratio tests to compare the fit of the full model to a reduced one without the term of interest. For measures of $\alpha$ and $\beta$ genetic diversity that provide measures of diversity that are either averaged over loci (average pairwise $\mathrm{F}_{\mathrm{ST}}$, proportion of first generation migrants, effective population size) or populations (Global $\mathrm{F}_{\mathrm{ST}}$ ) we analyzed the effect of relative invasion success on genetic diversity using ANOVA as implemented in R v3.3.1 (R Core Team 2016). Global $\mathrm{F}_{\mathrm{ST}}$ estimates include both spatial and temporal variation and ANOVAs were performed using independent loci as replicates while average pairwise $\mathrm{F}_{\mathrm{ST}}$, proportion of first generation migrants, effective population size estimates are averaged over loci for each population and the spatial and temporal population are used as replicates in the ANOVAs. We used an ANOVA to test whether there was a difference between successful and less-successful invasive species, in each of the pairs, for the average proportion of ancestry (admixture) attributed to one genetic group across populations. To account for multiple tests we assessed statistical significance using false discovery rate corrected $\mathrm{p}$ values at $\alpha=0.05$ within each taxa (Benjamini and Hochberg 1995).

To graphically investigate patterns of genetic diversity and invasion success across taxa we conducted principle components analysis on the mean diversity values (averaged across loci, populations and years) for measures of $\alpha$ and $\beta$ diversity separately for all species. Finally, we also fit a mixed-effects model for all species-pairs combined for all measures of genetic variability. These mixed-effects models were fit as above for each genetic diversity measure with the addition of a random effect for taxa.

\section{Results}

We successfully genotyped 2717 individuals from eight AIS differing in their invasion success (Table 1). Genetic diversity was characterized using a variety of summary and population genetic statistics (Table 2). There was strong statistical support for the inclusion of the random effect of locus for all tests ( $\alpha$ diversity) that included it. Sample year had no impact on diversity of any species (results not shown).

Statistically significant differences of $\alpha$ genetic diversity between the successful and less-successful species within each species pair were observed for the number of alleles for goby and tunicate species pairs and for allelic richness for the goby and oyster species pairs (Fig. 1; Table 2). Three of the species pairs (tunicates, gobies and waterfleas) approached statistically significant differences $(p<0.1)$ for observed heterozygosity (Table 2). The directions of the differences were consistent across measures of $\alpha$ diversity with reduced diversity in the less-successful species for gobies, tunicates and oysters and increased diversity for the less-successful waterflea.

Only one measure of $\beta$ diversity, the average pairwise $F_{\mathrm{ST}}$, was different between species in all species pairs (Table 2). This measure of diversity was higher (indicating more isolation and less gene flow) in the less-successful species for goby, tunicate and oyster species pairs and lower for the less-successful waterflea species pair. The waterflea species pair also demonstrated the same pattern of higher global $\mathrm{F}_{\mathrm{ST}}$ in the more successful species where there were no 


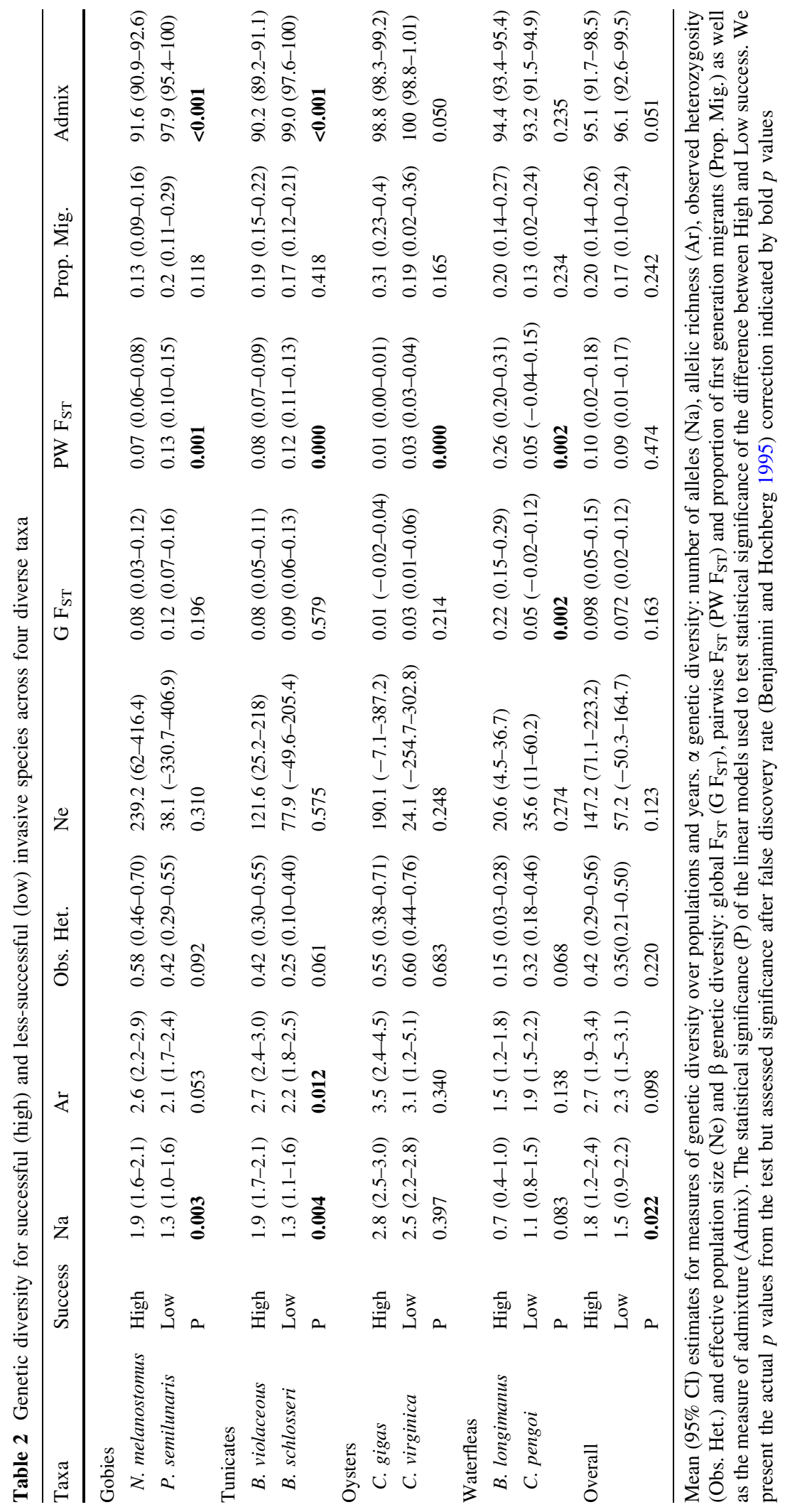




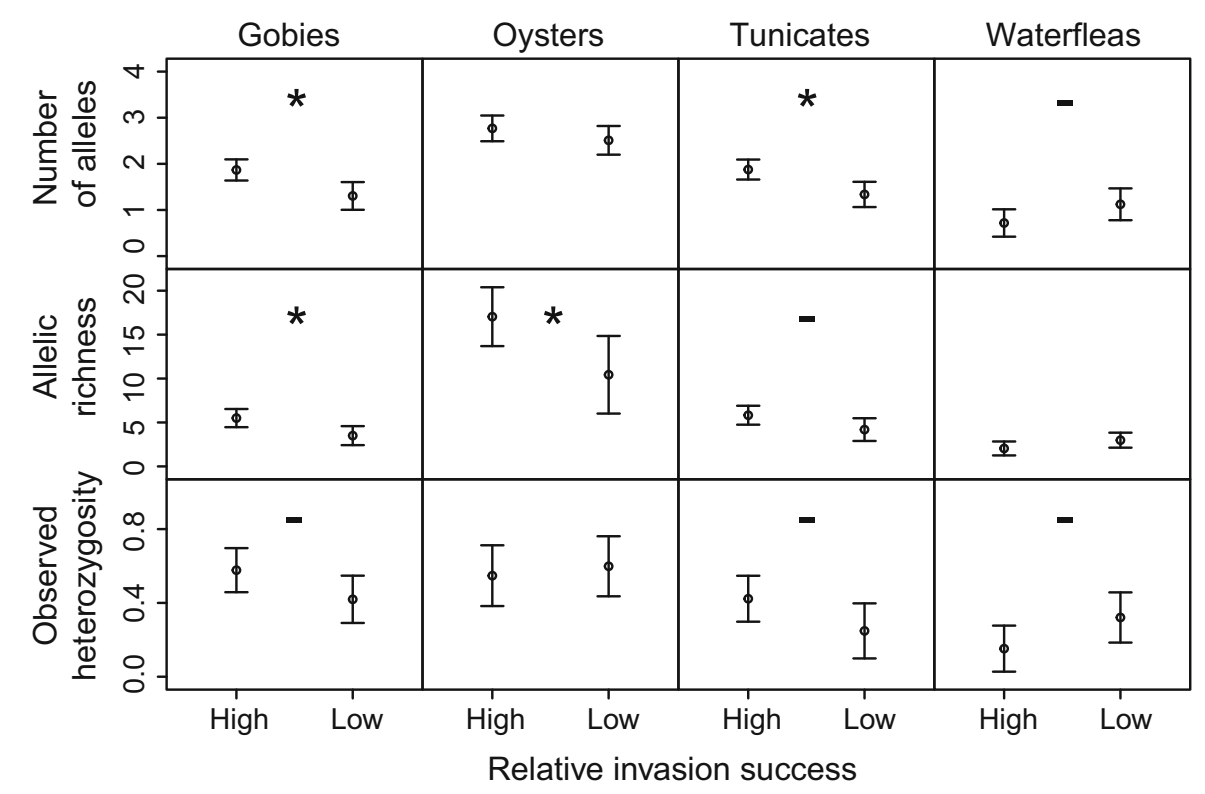

Fig. 1 Genetic diversity as characterized by number of alleles, allelic richness and observed heterozygosity (mean $\pm 95 \% \mathrm{CI}$ ) between successful (high) and less-successful (low) invasive

statistical differences for global $\mathrm{F}_{\mathrm{ST}}$ for any of the other species pairs. There was no statistical support for differences between successful and less-successful species in the proportion of first generation migrants detected (Table 2). We identified a higher degree of admixture (represented by a lower proportion of ancestry assigned to one group) for the highly successful goby, tunicate and oyster species but not for the waterfleas (Table 2).

When we considered all species together in a mixed effect model with taxa as a random factor, statistically significant differences were identified for the number of alleles where less-successful species were found to have fewer alleles (Table 2). All measures of $\alpha$ genetic diversity tended toward having reduced diversity in the less successful species (Fig. 1; Table 2); while measures of $\beta$ diversity tended to be lower in the more successful species. The lack of statistical significance for most genetic diversity measures overall is likely explained by the interaction of species-pair and relative invasion success. Based on the speciesspecific results we presented above, the waterflea species pair exhibits the opposite pattern of the tunicates and gobies. Indeed this interaction is visible in the PCA where the orientation of the successful/less-successful waterflea (diamonds) is opposite to species. Statistically significant comparisons are indicated by an asterisk where a dash indicates comparisons that approach statistical significance $(p<0.1)$. For exact $p$ values see Table 2

all other species for the axes loaded with number of alleles and allelic richness (Fig. 2a; PC1) and pairwise $\mathrm{F}_{\mathrm{ST}}$ (Fig. 2b; PC1).

\section{Discussion}

We have demonstrated that genetic diversity is associated with some invasion outcomes by controlling for differences in taxonomy and geography among aquatic invasive species (AIS). Generally, less-successful AIS were characterized by reduced $\alpha$ diversity. While $\beta$ diversity effects were less common, elevated among-population diversity was observed in the less-successful AIS. This indicates that in addition to exhibiting reduced allelic diversity, the lesssuccessful invaders in our study also experience reduced gene flow and hence lower connectivity. These results taken together suggest that genetic diversity may be limiting the success of the lesssuccessful AIS in our study. The significant effects of genetic diversity on invasion success were speciesspecific, highlighting the fact that while genetic diversity may be limiting some species invasions it is not necessarily a universal predictor of invasion success. 


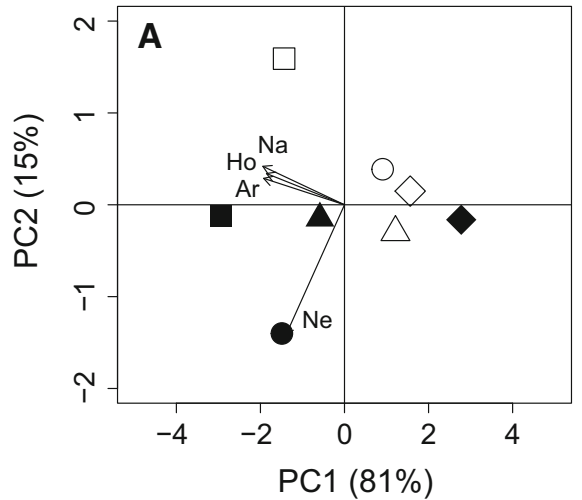

Fig. 2 Principle component biplots of successful (solid symbols) and less-successful (open symbols) invasive species from four taxa (circles goby fish, squares oysters, triangles tunicates, diamonds waterflea crustaceans) based on mean genetic diversity for four measures of within-population genetic

There are two possible explanations for why low within-population genetic diversity would result in less successful invasions: inbreeding depression and loss of adaptive potential. These mechanisms differ in the timing of their effects on invasion success. Inbreeding depression should affect invasive populations in the early stages of establishment when population sizes are at their smallest (Charlesworth and Charlesworth 1987). Given that all of the species we studied have been successfully established for over 10 generations, and we observed no obvious differences in effective population sizes, inbreeding depression is an unlikely explanation for the reduced invasion success observed for the less-successful AIS we studied. In contrast, adaptive potential is expected to influence the long-term success of biological invasions (Sakai et al. 2001). The loss of allelic diversity we observed for goby and tunicate species pairs suggest that reduced adaptive potential is the more likely explanation for the reduced invasion success of the less-successful AIS. Loss of allelic diversity is expected to have the largest impact on traits controlled by loci of large effect (Dlugosch et al. 2015). There are important examples of ecologically relevant traits controlled by a single locus that play a critical role in the colonization of novel habitats (e.g. evolution of reduced armour for sticklebacks colonizing fresh water, Colosimo et al. 2004); however there has been limited success in demonstrating the widespread nature of this phenomenon.

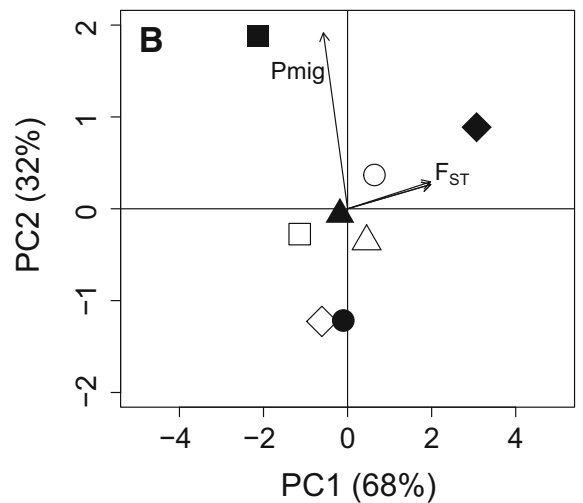

diversity (a): number of alleles (Na), allelic richness (Ar), observed heterozygosity (Ho), effective population size (Ne), and three measures of among-population genetic diversity (b): global $\mathrm{F}_{\mathrm{ST}}$ and pairwise $\mathrm{F}_{\mathrm{ST}}\left(\mathrm{F}_{\mathrm{ST}}\right)$, proportion of first generation migrants (Pmig)

The differences between successful and less-successful goby and tunicate species reflect approximately $20 \%$ reduction in allelic richness for both of the less-successful species. These reductions are similar to published estimates for the average intraspecific reduction of diversity (15-20\%) for introduced populations compared to native populations (Dlugosch and Parker 2008). The results we present could be due to the less-successful species having experienced a more substantial founder effect during their invasions. Propagule pressure is believed to be a key determinant of invasion success (Lockwood et al. 2005; Blackburn et al. 2015) and there is a positive, albeit complicated, relationship between propagule pressure and genetic diversity (Bock et al. 2015; Colautti and Lau 2015; Dlugosch et al. 2015). Alternatively, the genetic diversity of less-successful species may be limited because of evolutionary history where the source populations from which their invasions originated were initially of lower diversity than those of the highly successful invader.

We do not believe that differences in propagule pressure (e.g. founder effects) explain the difference in genetic diversity observed here for the goby and tunicate species pairs. In the case of the gobies, both species' invasions are derived from the northern Black Sea, arrived in North America at the same time and are believed to have originated from the Dneiper River, Ukraine in ballast water (Jude et al. 1992; Stepien and Tumeo 2006; Brown and Stepien 2009). This makes 
differences in propagule pressure difficult to justify, as it would appear they were introduced to North America by the same transport vector with similar timing of introduction. Indeed, Stepien and Tumeo (2006) characterize the $P$. semilunaris invasion as having similar genetic diversity to populations from its native range, suggesting little or no founder effects. The two tunicate invasions on the Atlantic coast of North America have very different histories. $B$. schlosseri has been present for over a century while B. violaceous was first detected in Canada in 2001 and the invasions originated from very different source locations: the Mediterranean and Japan respectively (Carver et al. 2006). Founder effect differences are also unlikely to explain the observed difference in genetic diversity between tunicate species. Based on the geographic proximity of the Mediterranean and the history of frequent ship travel across the Atlantic Ocean, a major vector for the spread of tunicates (Dijkstra et al. 2007), we speculate that the differences observed in genetic diversity are unlikely to have resulted in reduced propagule pressure relative to the more recent and geographically distant tunicate invader from the Pacific Ocean. While a clear demographic explanation for the reduced genetic diversity of these invaders is lacking, a systematic investigation comparing native and non-native populations of these species is required to discriminate between the possibilities that the less-successful species experienced a more severe founder effect or simply are more genetically depauperate compared to their highly successful congeners.

In contrast to the tunicates and gobies we studied, there is a stark difference in the propagule pressure experienced by the species of oyster we studied, that still failed to result in a significant effect on genetic diversity. Both species were introduced to the North American west coast for aquaculture purposes during the last century (Ruesink et al. 2005). While $C$. virginica was introduced earlier, its failure to spawn naturally and the faster growth rate of $C$. gigas made $C$. gigas the preferred species for aquaculture purposes. As a result, introductions of $C$. gigas continued over a span of many more years almost certainly resulting in higher propagule pressure than C. virginica (Carlton 1992; Ruesink et al. 2005). The greater propagule pressure and its extensive use in aquaculture have facilitated the $C$. gigas expansion throughout the Strait of Georgia. The reasons for the unsuccessful wide establishment of $C$. virginica are unclear but may relate to the lack of a suitable combination of temperatures and salinity for spawning and larval survival (Calabrese and Davis 1970), or perhaps the absence of widespread availability of suitable substrate and hydrographic conditions for the development of self-sustaining reefs (Lenihan 1999). Despite high levels of neutral genetic diversity, this species may still lack appropriate variation at specific functional loci to evolve around its physiological impediments to range expansion. These results highlight the difficulties of using noncoding regions of DNA to assess genetic diversity, although new promising techniques (De Wit et al. 2012) now allow characterization of functional protein coding for non-model organisms that may help address these limitations.

In addition to reduced allelic richness, we observed higher population differentiation for the less-successful invaders in all AIS species pairs except the waterflea species pair. There are many examples of secondary contact and hybridization of distinct genetic groups from a species' native range resulting in highly successful invasions (e.g. Kolbe et al. 2004). The boost in fitness that intraspecific hybridization provides during invasions may result from an increase in standing genetic variation, the creation of novel genotypes and heterosis (Bock et al. 2015; Dlugosch et al. 2015). The higher level of genetic differentiation among populations for the less-successful species indicates there is less gene flow among populations, and thus a reduced opportunity for intraspecific hybridization for those species. This reduced level of intraspecific hybridization for the less-successful invaders may have limited the opportunities for heterosis or for unique combinations of alleles to facilitate increased adaptive potential for these species. We explicitly quantified the level of admixture for these invasive species using non-equilibrium assuming methods and the patterns of increased admixture for highly successful invaders reflected our prediction of increased intraspecific hybridization (admixture) in the highly successful invader. While these results are consistent with our other results and our expectations, they should be interpreted with caution due to the fact that the number of clusters we chose and how well these choices reflect the biological reality may influence the outcome of this analysis. The role of intraspecific hybridization in determining invasion success is an important but 
understudied aspect of the genetics of invading species (Dlugosch et al. 2015) and our results highlight the need for a better understanding of the nuanced relationship between among-population ( $\beta$ ) diversity and invasion success.

The opposing patterns of genetic diversity we observed for the waterflea species pair compared to the other three AIS pairs may be the result of several phenomena. B. longimanus are known to have experienced a founder effect (Colautti et al. 2005). While this may represent a rare case of a highly successful invasion despite low genetic diversity, both species of waterfleas exhibit cyclical parthenogenesis indicating that the dynamics of natural selection and sexual reproduction will produce different patterns of genetic diversity compared with obligate sexual reproducers (Rouger et al. 2016). Selection on B. longimanus during periods of asexual reproduction may have rapidly eroded genetic diversity leaving a low level of diversity but a highly adapted species. The inconsistency for this species could also be the result of ecological factors. Owing to their preference for generally cooler waters (Cavaletto et al. 2010) and the longer history of their invasion, $B$. longimanus are found in many smaller inland lakes ( 3 of 6 sites in our study). Recent work has demonstrated the importance of B. longimanus predation on $C$. pengoi distribution in large lakes (Ptáčniková et al. 2015) suggesting that the prior invasion of $B$. longimanus may limit the success of $C$. pengoi invasions. Finally, it is possible that the higher diversity of $C$. pengoi ultimately allows it to out-perform $B$. longimanus in the future. This outcome would parallel that of dreissenid mussels in the Great Lakes where zebra mussels established first and spread rapidly but have since been outcompeted in certain habitats by the equally genetically diverse quagga mussels (Brown and Stepien 2010). Our results for the waterflea species pair highlight the fact that genetic diversity is not the sole predictor of invasion success, but we emphasize that the results for at least two of our species pairs indicate that genetic diversity may be limiting some species invasion success.

We have demonstrated a role for both within- and among-population genetic diversity in limiting the success of specific invasive species in North America. Our use of a novel comparative approach involving congeneric invaders of differing success has revealed differences that may not have been revealed by comparing native and invasive populations. This has relevance for not only the risk assessment of invasive species, but also the conservation of genetic diversity of species in general. Our results show that both $\alpha$ and $\beta$ genetic diversity play important roles in determining invasion success, and that the conflicting results reported in the literature may be driven by methodological limitations and species-specific life history or invasion history differences. Like other recent authors (Dlugosch et al. 2015), we call for more robust and detailed characterization of the role of genetic diversity in invasions that accounts for life history and invasion history of organisms while including measures of both within populations diversity ( $\alpha$ diversity) as well as the distribution of genetic diversity among invasive populations ( $\beta$ diversity). Advances in sequencing technology (De Wit et al. 2012; Ellegren 2014) now provide the opportunity to bypass the limitations of neutral microsatellites for non-model organisms and assess functional protein-coding gene variation to better reveal the role of genetic diversity in promoting evolution in biological invasions and the consequences this has for predicting invasion success. Our study provides a framework for understanding the species-specific nature of genetic diversity reductions during invasion and provides a point of reference for future studies to assess the importance of evolutionary processes in determining invasion success.

Acknowledgements We are greatly indebted to Dr. Tom Therriault and Dr. Chris McKindsey and their respective Department of Fisheries and Oceans Canada sampling teams who collected the oysters and tunicates used in this study. We would also like to thank Colin Van Overdijk for his assistance collecting the waterfleas and Katerina Stojanovich and Kelly McLean for their assistance collecting gobies. This work was supported by funds from the Canadian Aquatic Invasive Species Network II grant (NSERC) to ATF and DDH. HPW received support from an Ontario Trillium Scholarship and KWW received support from NSERC.

\section{References}

Baker H, Stebbins G (eds) (1965) The genetics of colonizing species. Academic Press, New York

Barrett SCH (2015) Foundations of invasion genetics: the Baker and Stebbins legacy. Mol Ecol 24:1927-1941. doi:10. 1111/mec.13014

Bates D, Mächler M, Bolker B, Walker S (2015) Fitting linear mixed-effects models using lme4. J Stat Softw 67:1-48. doi:10.18637/jss.v067.i01

Benjamini Y, Hochberg Y (1995) Controlling the false discovery rate: a practical and powerful approach to multiple testing. J R Stat Soc B 57:289-300 
Blackburn TM, Lockwood JL, Cassey P (2015) The influence of numbers on invasion success. Mol Ecol 24:1942-1953. doi: $10.1111 / \mathrm{mec} .13075$

Bock DG, Caseys C, Cousens RD et al (2015) What we still don't know about invasion genetics. Mol Ecol 24:2277-2297. doi:10.1111/mec.13032

Brown JE, Stepien CA (2009) Invasion genetics of the Eurasian round goby in North America: tracing sources and spread patterns. Mol Ecol 18:64-79. doi:10.1111/j.1365-294X. 2008.04014.x

Brown JE, Stepien CA (2010) Population genetic history of the dreissenid mussel invasions: expansion patterns across North America. Biol Invasions 12:3687-3710. doi:10. 1007/s10530-010-9763-2

Calabrese A, Davis HC (1970) Tolerances and requirements of embryos and larvae of bivalve molluscs. Helgoländer Meeresun 20:553-564. doi:10.1007/BF01609928

Carlton JT (1992) Introduced marine and estuarine mollusks of North America: an end-of-the-20th-century perspective. J Shellfish Res 11:489-505

Carver C, Mallet A, Vercaemer B (2006) Biological synopsis of the colonial tunicates (Botryllus schlosseri and Botrylloides violaceus). Can Man Rep Fish Aquat Sci 2747:42

Cavaletto JF, Vanderploeg HA, Pichlová-PtáČníková R et al (2010) Temporal and spatial separation allow coexistence of predatory cladocerans: Leptodora kindtii, Bythotrephes longimanus and Cercopagis pengoi, in southeastern Lake Michigan. J Gt Lakes Res 36:65-73. doi:10.1016/j.jglr.2010.04.006

Charlesworth D, Charlesworth B (1987) Inbreeding depression and its evolutionary consequences. Annu Rev Ecol Syst 18:237-268. doi:10.1146/annurev.ecolsys.18.1.237

Colautti RI, Lau JA (2015) Contemporary evolution during invasion: evidence for differentiation, natural selection, and local adaptation. Mol Ecol 24:1999-2017. doi:10. $1111 /$ mec. 13162

Colautti RI, MacIsaac HJ (2004) A neutral terminology to define "invasive" species. Divers Distrib 10:135-141. doi:10. 1111/j.1366-9516.2004.00061.x

Colautti RI, Manca M, Viljanen M et al (2005) Invasion genetics of the Eurasian spiny waterflea: evidence for bottlenecks and gene flow using microsatellites. Mol Ecol 14:1869-1879. doi:10.1111/j.1365-294X.2005.02565.x

Colosimo PF, Peichel CL, Nereng K et al (2004) The genetic architecture of parallel armor plate reduction in threespine sticklebacks. PLoS Biol 2:635-641. doi:10.1371/journal. pbio.0020109

De Wit P, Pespeni MH, Ladner JT et al (2012) The simple fool's guide to population genomics via RNA-Seq: an introduction to high-throughput sequencing data analysis. Mol Ecol Resour 12:1058-1067. doi:10.1111/1755-0998.12003

Dijkstra J, Harris LG, Westerman E (2007) Distribution and long-term temporal patterns of four invasive colonial ascidians in the Gulf of Maine. J Exp Mar Bio Ecol 342:61-68. doi:10.1016/j.jembe.2006.10.015

Dlugosch KM, Parker I (2008) Founding events in species invasions: genetic variation, adaptive evolution, and the role of multiple introductions. Mol Ecol 17:431-449. doi:10.1111/j.1365-294X.2007.03538.x

Dlugosch KM, Anderson SR, Braasch J et al (2015) The devil is in the details: genetic variation in introduced populations and its contributions to invasion. Mol Ecol 24:2095-2111. doi:10.1111/mec.13183

Do C, Waples RS, Peel D et al (2014) NeEstimator v2: reimplementation of software for the estimation of contemporary effective population size $(\mathrm{Ne})$ from genetic data. Mol Ecol Resour 14:209-214. doi:10.1111/1755-0998. 12157

Ellegren H (2014) Genome sequencing and population genomics in non-model organisms. Trends Ecol Evol 29:51-63. doi:10.1016/j.tree.2013.09.008

Elphinstone MS, Hinten GN, Anderson MJ, Nock CJ (2003) An inexpensive and high-throughput procedure to extract and purify total genomic DNA for population studies. Mol Ecol Notes 3:317-320. doi:10.1046/j.1471-8286.2003.00397.x

Fisher R (1930) The genetical theory of natural selection. Clarendon Press, Oxford

Gillespie G (2007) Distribution of non-indigenous intertidal species on the Pacific Coast of Canada. Nippon Suisan Gakkaishi 73:1133-1137. doi:10.2331/suisan.73.1133

Goudet J, Jombart T (2015) hierfstat: estimation and tests of hierarchical F-statistics. $\mathrm{R}$ package version 0.04-22. https://CRAN.R-project.org/package=hierfstat

Grant KA, Shadle MJ, Andraso G (2012) First report of tubenose goby (Proterorhinus semilunaris) in the eastern basin of Lake Erie. J Gt Lakes Res 38:821-824. doi:10.1016/j.jglr. 2012.09.019

He X, Johansson ML, Heath DD (2016) Role of genomics and transcriptomics in selection of reintroduction source populations. Conserv Biol 30:1010-1018. doi:10.1111/cobi. 12674

Johannsson OE, Mills EL, O'Gorman R (1991) Changes in the nearshore and offshore zooplankton communities in Lake Ontario: 1981-88. Can J Fish Aquat Sci 48:1546-1557. doi:10.1139/f91-183

Jombart T (2008) Adegenet: a R package for the multivariate analysis of genetic markers. Bioinformatics 24:1403-1405. doi:10.1093/bioinformatics/btn129

Jombart T, Devillard S, Balloux F et al (2010) Discriminant analysis of principal components: a new method for the analysis of genetically structured populations. BMC Genet 11:94. doi:10.1186/1471-2156-11-94

Jude DJ, Reider RH, Smith GR (1992) Establishment of Gobiidae in the Great Lakes basin. Can J Fish Aquat Sci 49:416-421

Kinziger AP, Nakamoto RJ, Anderson EC, Harvey BC (2011) Small founding number and low genetic diversity in an introduced species exhibiting limited invasion success (speckled dace, Rhinichthys osculus). Ecol Evol 1:73-84. doi:10.1002/ece3.8

Kocovsky PM, Tallman JA, Jude DJ et al (2011) Expansion of tubenose gobies Proterorhinus semilunaris into western Lake Erie and potential effects on native species. Biol Invasions 13:2775-2784. doi:10.1007/s10530-011-9962-5

Kolbe JJ, Glor RE, Rodríguez Schettino L et al (2004) Genetic variation increases during biological invasion by a Cuban lizard. Nature 431:177-181. doi:10.1038/nature02807

Kolbe JJ, Leal M, Schoener TW et al (2012) Founder effects persist despite adaptive differentiation: a field experiment with lizards. Science 335:1086-1089. doi:10.1126/science. 1209566 
Lenihan HS (1999) Physical-biological coupling on oyster reefs: how habitat structure influences individual performance. Ecol Monogr 69:251-275. doi:10.1890/00129615(1999)069[0251:PBCOOR]2.0.CO;2

Lockwood JL, Cassey P, Blackburn T (2005) The role of propagule pressure in explaining species invasions. Trends Ecol Evol 20:223-228. doi:10.1016/j.tree.2005.02.004

MacIsaac HJ, Grigorovich IA, Hoyle JA et al (1999) Invasion of Lake Ontario by the Ponto-Caspian predatory cladoceran Cercopagis pengoi. Can J Fish Aquat Sci 56:1-5. doi:10. 1139/cjfas-56-1-1

Nei M, Maruyama T, Chakraborty R (1975) The bottleneck effect and genetic variability in populations. Evolution 29:1-10

Paetkau D, Slade R, Burden M, Estoup A (2004) Genetic assignment methods for the direct, real-time estimation of migration rate: a simulation-based exploration of accuracy and power. Mol Ecol 13:55-65. doi:10.1046/j.1365-294X. 2003.02008.x

Paradis E (2010) pegas: an R package for population genetics with an integrated-modular approach. Bioinformatics 26:419-420

Pettitt-Wade H (2016) Niche breadth and invasion success. $\mathrm{Ph}$.D. dissertation, Great Lakes Institute for Environmental Research, University of Windsor, Windsor, Ontario, Canada

Pettitt-Wade H, Wellband KW, Heath DD, Fisk AT (2015) Niche plasticity in invasive fishes in the Great Lakes. Biol Invasions 17:2565-2580. doi:10.1007/s10530-015-0894-3

Ptáčniková R, Vanderploeg HA, Cavaletto JF (2015) Big versus small: does Bythotrephes longimanus predation regulate spatial distribution of another invasive predatory cladoceran, Cercopagis pengoi? J Great Lakes Res 41:143-149. doi:10.1016/j.jglr.2015.10.006

R Core Team (2016) R: a language and environment for statistical computing. R Foundation for Statistical Computing, Vienna, Austria. https://www.R-project.org/

Rannala B, Mountain JL (1997) Detecting immigration by using multilocus genotypes. Proc Natl Acad Sci USA 94:9197-9201

Rouger R, Reichel K, Malrieu F et al (2016) Effects of complex life cycles on genetic diversity: cyclical parthenogenesis. Heredity 117:336-347. doi:10.1038/hdy.2016.52
Ruesink JL, Lenihan HS, Trimble AC et al (2005) Introduction of non-native oysters: ecosystem effects and restoration implications. Annu Rev Ecol Evol Syst 36:643-689. doi:10.1146/annurev.ecolsys.36.102003.152638

Sakai AK, Allendorf FW, Holt JS et al (2001) The population biology of invasive species. Annu Rev Ecol Syst 32:305-332

Signorile AL, Wang J, Lurz PWW et al (2014) Do founder size, genetic diversity and structure influence rates of expansion of North American grey squirrels in Europe? Divers Distrib 20:918-930. doi:10.1111/ddi.12222

Stepien CA, Tumeo MA (2006) Invasion genetics of PontoCaspian gobies in the Great Lakes: a "cryptic" species, absence of founder effects, and comparative risk analysis. Biol Invasions 8:61-78. doi:10.1007/s10530-005-0237-x

Therriault TW, Grigorovich IA, Kane DD et al (2002) Range expansion of the exotic zooplankter Cercopagis pengoi (Ostroumov) into western Lake Erie and Muskegon Lake. J Gt Lakes Res 28:698-701. doi:10.1016/S03801330(02)70615-1

Uller T, Leimu R (2011) Founder events predict changes in genetic diversity during human-mediated range expansions. Glob Chang Biol 17:3478-3485. doi:10.1111/j. 1365-2486.2011.02509.x

Waples R, Do C (2008) LDNE: a program for estimating effective population size from data on linkage disequilibrium. Mol Ecol Resour 8:753-756. doi:10.1111/j.17550998.2007.02061.x

Weir BS, Cockerham CC (1984) Estimating F-statistics for the analysis of population structure. Evolution 38:1358-1370. doi: $10.2307 / 2408641$

Yan ND, Leung B, Lewis MA, Peacor SD (2011) The spread, establishment and impacts of the spiny water flea, Bythotrephes longimanus, in temperate North America: a synopsis of the special issue. Biol Invasions 13:2423-2432. doi:10.1007/s10530-011-0069-9

Zenni RD, Nuñez MA (2013) The elephant in the room: the role of failed invasions in understanding invasion biology. Oikos 122:801-815. doi:10.1111/j.1600-0706.2012.00254.x 